\title{
Utilization of family planning services by married Sudanese women of reproductive age
}

A.H. Ibnouf, ${ }^{1}$ H.W. van den Borne ${ }^{1}$ and J.A.M. Maarse ${ }^{1}$

$$
\begin{aligned}
& \text { استفادة المسودانيات المتـزوجات اللاتي هن في عمر الإنجاب من خحدمات تنظيم الأسرة }
\end{aligned}
$$

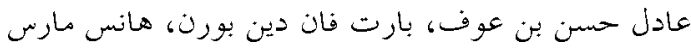

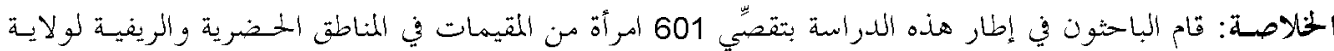

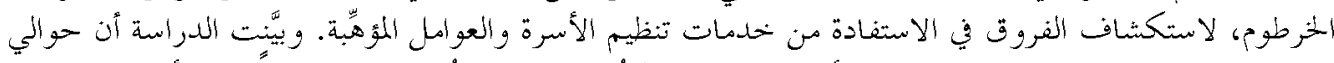

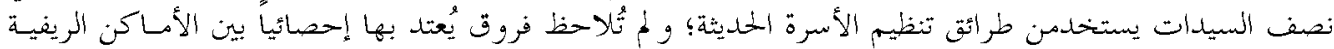

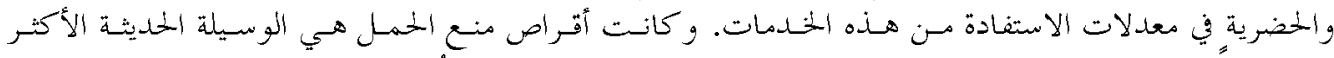

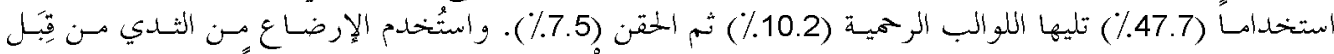

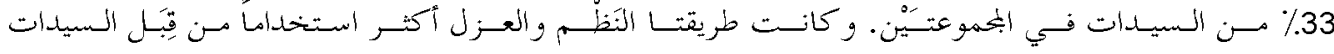

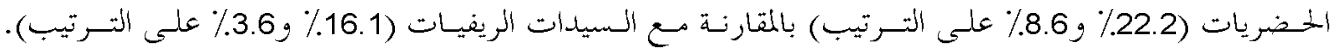

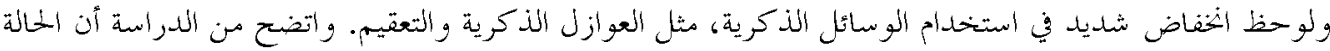

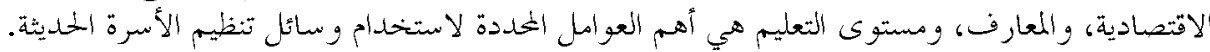

ABSTRACT To explore differences in utilization of family planning services and predisposing factors we surveyed 601 women from urban and rural areas of Khartoum state. About half were using modern family planning techniques; there were no significant differences in utilization rates between urban and rural settings. Contraceptive pills were the most frequently used modern method $(47.7 \%)$ followed by intrauterine devices (10.2\%) and injections (7.5\%). Breastfeeding was used by around $33 \%$ of both groups. The rhythm method and withdrawal were more often used by urban women $(22.2 \%$ and $8.6 \%$ respectively) than rural women $(16.1 \%$ and $3.6 \%$ respectively). Use of male methods (condom; sterilization) was extremely low. Socioeconomic status, knowledge and education level were the most important determinants of using modern methods.

\begin{abstract}
Utilisation des services de planification familiale par les femmes soudanaises mariées en âge de procréer

RÉSUMÉ Afin d'analyser les différences en matière d'utilisation des services de planification familiale et les facteurs prédisposant à cette dernière, nous avons mené une enquête auprès de 601 femmes des zones urbaines et rurales de l'État de Khartoum. Environ la moitié d'entre elles utilisait des méthodes de planification familiale modernes, les taux d'utilisation ne laissant apparaître aucune différence significative entre les secteurs urbains et ruraux. La pilule contraceptive était la méthode moderne la plus répandue $(47,7 \%)$, suivie par les dispositifs intra-utérins $(10,2 \%)$ et les injections contraceptives $(7,5 \%)$. Dans les deux groupes, la pratique de l'allaitement maternel atteignait près de $33 \%$. L'abstinence sexuelle périodique (méthode Ogino-Knaus ou cyclique) et la méthode dite du retrait (ou coït interrompu) étaient plus fréquemment utilisées par les femmes des zones urbaines (respectivement $22,2 \%$ et $8,6 \%$ ) qu'en zone rurale (16,1 \% et 3,6 \%). Quant aux méthodes de contraception masculine (préservatif, stérilisation), leur usage était tout à fait négligeable. Le statut socioéconomique, le niveau des connaissances et le degré d'instruction sont apparus comme les déterminants majeurs de l'utilisation des méthodes contraceptives modernes.
\end{abstract}

${ }^{1}$ Department of Health Policy and Management, University of Maastricht, Maastricht, Netherlands (Correspondence to A.H. Ibnouf: A.lbnouf@beoz.unimaas.nl). 


\section{Introduction}

Countries with a large population and high density relative to available resources suffer tremendously from high fertility rates. High fertility rates are strongly associated with inadequate spacing between births, which in turn is associated with high maternal and infant mortality.

An estimated 600000 maternal deaths occur worldwide each year, $99 \%$ of them in developing countries. The World Health Organization estimates that $13 \%$ of these are due to unsafe abortions. Worldwide, approximately 50 million women resort to induced abortion each year, frequently resulting in mortality and adverse health consequences $[1,2]$. Other causes of high maternal death rates in developing countries include complications of pregnancy and complications of childbirth.

In Sudan, maternal and infant mortality and fertility indicators are among the highest in the Region. Maternal mortality is estimated at 600 per 100000 live births and infant mortality at 70 per 1000 live births; the fertility rate is estimated at 4.6 children per woman [3]. The total fertility rate of a nation is directly related to the prevalence of contraceptive use. On average, for every 15 percentage points increase in contraceptive use in the community there is a reduction of 1 birth per woman [4]. This suggests that countries with high total fertility rates tend to have low contraceptive use and vice versa. Unintended pregnancies have significant consequences and occur most frequently in adolescents, low-income groups and women from minority groups. Improving contraceptive compliance among high-risk adolescents is a key to reducing the rates of unintended pregnancy in this group of the population [5].

National family planning programmes and services in developing countries have been associated with notable increases in contraceptive use and consequent declines in fertility [6]. Oral contraceptives and condoms are the base of many programmes, but some earlier programmes relied, and continue to rely heavily, on methods such as the intrauterine device (IUD), that are less prominent in programmes that started later. Over time newer methods such as injectables and implants have found their own niches. The main trend has been towards permanent methods; sterilization, which has become simpler and more demanded, now accounts for half of all contraceptive use [6].

Family planning services were introduced in Sudan in 1965 with the foundation of the Sudan Family Planning Association, which provides services throughout the country (Federal Ministry of Health, Sudan, unpublished report, 1992). The total fertility rate for the age group 15-49 years suggests a sharp fall in fertility level in recent years. Total fertility was 6.5 births per woman during the 10-14 years before the 1999 safe motherhood survey, 6.2 births per woman 5-9 years before the survey, and 4.9 births per woman 0-4 years before the survey [7].

In January 2002 the government drafted a national population policy. This supports efforts to empower married couples to receive information about a range of contraceptive methods and access to the methods of their choice. However, availability and accessibility to services still vary greatly, especially between urban and rural areas. While many Sudanese women have heard of family planning, research indicates significant unmet needs. Although nearly $20 \%$ of married women in Sudan reported not wanting another child, contraceptive use is still low [8]. The proportion of women using modern methods of contraception in Northern Sudan increased slightly from $4 \%$ in $1977-1978$ to $6 \%$ in 1989 and $7 \%$ in 1992-1993 [8,9].

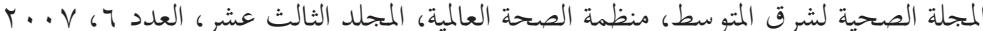


Family planning practice is determined by many factors that can be considered obstacles to the use of family planning services. Caldwell and Caldwell emphasized the cultural imperatives of African communities that are important in maintaining high levels of fertility [10]. In many African cultures it is taboo to be childless: high fertility, therefore, enjoys both community and divine approval $[10,11]$. A woman's age, residence (urban or rural), education and income may have substantial effects on contraceptive use and are likely to affect how women choose family planning services [12].

Behaviour regarding contraception is known to vary widely according to education, which is likely to be positively correlated with the use of private sector services. Significant rural-urban difference exists in fertility levels in Sudan. On average, age specific fertility rates are lower in urban than in rural areas, which suggests greater use of contraception by urban women [7].

\section{Objectives}

This study describes the current family planning situation in Khartoum State, Sudan. The information gathered will be useful in designing programmes which will contribute in making family planning services more available and accessible to Sudanese women.

Specific objectives of the study were to:

- examine the differences in utilization between urban and rural areas in Khartoum State;

- describe the family planning methods that are used;

- assess the impact of socioeconomic status, women's level of education, age, area of residence and knowledge on the utilization of family planning services;

- examine the effect of government policy and providers on services distribution.

\section{Methods}

\section{Study design}

The study was a cross-sectional survey among a representative sample of married women aged 15-49 years from both urban and rural localities in Khartoum State in Sudan. The women were from varying socioeconomic, educational, employment and cultural backgrounds.

\section{Conceptual framework}

The model applied in this study was an extension of Dutton's access and utilization model for health services [13], which, in turn, builds upon Andersen and Newman's predisposing-enabling-need (PEN) explanatory model for health services utilization [14].

The dependent variable in this study was the utilization of modern family planning techniques. The independent variables were the demographic and socioeconomic variables of age, residence, socioeconomic status, and education level, and also the predisposing factor of knowledge about family planning. Place from which services are obtained (location) and knowledge are variables affected by government policy on family planning.

Utilization was defined as the respondents' state of using or having used $\geq 1$ modern family planning techniques [contraceptive pill, intrauterine device, injection, male condom, diaphragm (known locally as "female condom"), male sterilization, and female sterilization]. Traditional methods used were breastfeeding, rhythm method and withdrawal. No use was scored 0 and defined as never used; use of $\geq 1$ modern methods was scored 1 and defined as using. Education was defined as completed educational status. It was scored 1 (no schooling), 2 (primary education), 3 (intermediate education), 4 (secondary education) and 5 
(university and higher education). Age was defined as respondents' age at the time of interview. It was recoded as younger age (15-29 years) and older age (30-45 years). Location and distribution of services were defined as place from which respondents got access to techniques when they decided to use them, and was scored 0 for local health centre, 1 for other health centre, 2 for public hospital, 3 for family planning clinic, 4 for mother-child centre, 5 for private hospital/clinic, 6 for nongovernmental organization clinic, 7 for pharmacy, 8 for friends and relatives, 9 for other and 10 for not applicable. Knowledge about family planning methods was defined as the respondent status of having heard about the 10 different traditional (breastfeeding; rhythm; withdrawal) and modern techniques of family planning: heard about $0-7$ methods and techniques was defined as poor knowledge and heard about $8-10$ was defined as good knowledge.

Data about reasons for not using family planning services were collected from the non-users; answers included unavailability of services and services available only at full price.

The collection of data on socioeconomic status was guided by the methods used in the safe motherhood survey of 1999 [7]. Data collected covered ownership of durable goods (TV, refrigerator, car etc.) and standard of living (fuel used for cooking, source of water, etc.) were also considered as indicators. Using factor analysis, a new variable on socioeconomic status of individuals was derived and was scored 1 (low), 2 (medium) or 3 (high).

\section{Selection of the study area and sampling}

Utilization of family planning services were studied in Khartoum State by comparing urban and rural localities of the state that differed in socioeconomic status and living conditions. The total population in Khartoum State was 5548784 (Khartoum State Ministry of Health, Department of Statistics, unpublished data, 2004). The state comprises 3 provinces, Khartoum, Omdurman and Bahri, with heterogeneous urban and rural societies in each province. Khartoum province contains 1 rural locality and 6 urban localities; Omdurman province contains 2 rural and 7 urban localities while Bahri province contains 6 rural and 4 urban localities. The ratio of the total rural localities to the total locality number in the state is $9 / 26=0.346$, and the ratio of the total urban localities to the total state localities is $17 / 26$ $=0.654$. Applying the above ratios within each province (owing to the heterogeneous nature of the population in the state), the single rural locality in Khartoum province was selected; the urban localities were selected using the equation: $0.654 \times 6=4$. From the 2 rural localities in Omdurman province, 1 was selected by applying the equation: $2 \times 0.346=1$, while from the 7 urban localities, 5 were selected applying the equation: $7 \times 0.654=5$. In Bahri province, 2 out of the 6 rural localities were selected by the equation: $6 \times 0.346=2$, while 3 out of the 4 urban localities were selected by the equation: $4 \times 0.654=3$. So, a total of 16 localities were selected for the research throughout the state, 12 urban and 4 rural. Then within each province, the localities were randomly selected.

A sample size of 601 married women from the target population was used for the study. The sampling frame was the 2002 total women targeted for family planning in Khartoum State, Ministry of Health and the total households' baseline data for the 2003 population census of the Central Bureau of Statistics (Khartoum State Ministry of Health, unpublished data, 2003). The ratio of women aged 15-49 years to the total

المجلة الصحية لشرق المتوسط، منظمة الصحة العالمية، المجلد الثالث عشر، العدد Y، V. Y. 
population of the state for the year 2002 was considered the population frame. The total sample for the study group in all the state was derived using the formula:

$$
n=\left(\mathrm{Z}^{2} \times \mathrm{P} \times \mathrm{Q} \times \operatorname{deff}\right) / \mathrm{d}^{2}
$$

Where $n$ is the projected number of the targeted study population (women 15-49 years old), $\mathrm{Z}$ is the $\mathrm{Z}$-score, which is a standard $(1.96 \approx 2)$; $\mathrm{P}$ is the expected prevalence of the study group population (targeted population ratio), $25.04 \%(0.2504)$; $\mathrm{Q}=1-\mathrm{P}$; deff is the design effect (1.5-2) $\approx 2$; and $\mathrm{d}$ is the marginal error (degree of precision). Alpha error $=0.05$.

So:

$$
n=(22 \times 0.2504 \times 0.7496 \times 2) / 0.052=601
$$

The total sample size was divided between the localities according to the ratio of number of households in each locality to the total number of households (482 854 households). In each locality, the every other household rule was applied for interviewing respondents. In all the localities, all selected households were covered. The overall response rate for the household questionnaire was $100 \%$. The major factor explaining this high response rate was that the data collectors were females, who could easily get access to women; males would find it difficult to interview women due to the cultural and religious values in the country.

\section{Data collection and analysis}

The data were collected in the period August 2002-December 2002 after collectors were trained and questionnaires were tested. Bivariate (cross-tabulation and chi-squared tests, independent sample $t$-tests), factor analysis and logistic regression analysis were used for the analysis of data using
SPSS, version 11. Factor analysis was applied to construct an indicator for socioeconomic status. Logistic regression analysis was used to measure the relative impact of the selected independent variables on utilization of family planning service.

Logistic regression analysis was used to identify the determinants of modern contraceptive use. The dependent variable "contraceptive use" was coded 1 if the respondent was categorised as "user", and 0 if not. The statistical model was estimated with a range of independent variables and assessed the effect of changing one of the independent variables on the odds of the respondent being a user of family planning methods). One category of each of the independent variables was chosen as the reference category. Age was considered a continuous independent variable. The coefficient $[\operatorname{Exp}(\mathrm{B})]$ for the reference category was set at 1.0, and the coefficients for other values of the variable were interpreted relative to this reference category. A coefficient $>1.0$ means that the value of the variable in question increases the odds of the individual using family planning compared with the reference category; a coefficient $<1.0$ means that the odds are reduced compared with the reference category.

\section{Results}

\section{Utilization of family planning services}

After excluding traditional methods of family planning, about half (51.4\%) the women in the entire sample used modern family planning methods (Table 1). Women from urban and rural settings had almost the same level of use. Women with high socioeconomic status $(73.1 \%)$ reported using modern family planning methods more often than those with medium $(51.1 \%)$ and low $(28.0 \%)$ socioeconomic status. Signifi- 


\begin{tabular}{|c|c|c|c|c|c|c|}
\hline \multirow[t]{2}{*}{ Characteristic } & \multirow[t]{2}{*}{ Total } & \multicolumn{2}{|c|}{ Use } & \multicolumn{2}{|c|}{ Do not use } & \multirow[t]{2}{*}{$\chi^{2}$} \\
\hline & & No. & $\%$ & No. & $\%$ & \\
\hline Overall & 601 & 309 & 51.4 & 292 & 48.6 & \\
\hline \multicolumn{7}{|l|}{ Area } \\
\hline Rural & 56 & 30 & 53.6 & 26 & 46.4 & \multirow[t]{2}{*}{$0.115 \mathrm{NS}$} \\
\hline Urban & 545 & 279 & 51.2 & 266 & 48.8 & \\
\hline \multicolumn{7}{|c|}{ Socioeconomic status } \\
\hline Low & 200 & 56 & 28.0 & 144 & 72.0 & \multirow[t]{3}{*}{$82.975^{\star * *}$} \\
\hline Medium & 182 & 93 & 51.1 & 89 & 48.9 & \\
\hline High & 219 & 160 & 73.1 & 59 & 34.5 & \\
\hline \multicolumn{7}{|l|}{ Age group } \\
\hline $15-30$ & 285 & 133 & 46.7 & 152 & 53.3 & \multirow[t]{3}{*}{$4.576^{*}$} \\
\hline $31-45$ & 313 & 174 & 55.6 & 139 & 44.4 & \\
\hline Missing data & 3 & & & & & \\
\hline \multicolumn{7}{|c|}{ Level of education } \\
\hline No schooling & 110 & 29 & 26.4 & 81 & 73.6 & \multirow[t]{5}{*}{$44.059^{* * *}$} \\
\hline Primary & 165 & 78 & 47.3 & 87 & 52.7 & \\
\hline Intermediate & 106 & 66 & 62.3 & 40 & 37.7 & \\
\hline Secondary & 162 & 103 & 63.6 & 59 & 36.4 & \\
\hline University+ & 58 & 33 & 56.9 & 25 & 43.1 & \\
\hline \multicolumn{7}{|l|}{ Knowledge } \\
\hline Poor & 296 & 114 & 38.5 & 182 & 61.5 & \multirow[t]{3}{*}{$39.446^{* * *}$} \\
\hline Good & 304 & 195 & 64.1 & 109 & 35.9 & \\
\hline Missing data & 1 & & & & & \\
\hline
\end{tabular}

cantly more of the older age group reported using modern methods $(55.6 \%)$ compared to the younger women $(46.7 \%)$. Utilization increased steadily with increase in level of education but fell slightly for women with university and higher education. Almost two thirds of the women with good knowledge of family planning reported using the modern methods while just over one third of those with poor knowledge reported using modern methods $(P<0.001)$.

\section{Family planning methods and sources}

Table 2 shows the use of different family planning methods in Khartoum State. Using contraceptive pills was reported by just un- der half the women surveyed $(47.7 \%)$ followed by intrauterine devices $(10.2 \%)$ and injections $(7.5 \%)$. Levels of use of female and male condoms and male and female sterilization were very low and were only reported by urban women. No significant differences were found between women in urban and rural areas.

Breastfeeding rate was about the same for rural (33.9\%) and urban (32.2\%) women (Table 2). The rhythm method and withdrawal were used by urban women $(22.2 \%$ and $8.6 \%$ respectively) more often than rural women ( $16.1 \%$ and $3.6 \%$ respectively) but the differences were not statistically significant. 


\begin{tabular}{|c|c|c|c|c|c|c|}
\hline \multirow{3}{*}{ Method $^{a}$} & \multicolumn{6}{|c|}{ Using family planning } \\
\hline & \multicolumn{2}{|c|}{ Rural } & \multicolumn{2}{|c|}{ Urban } & \multicolumn{2}{|c|}{ Overall } \\
\hline & No. & $\%$ & No. & $\%$ & No. & $\%$ \\
\hline \multicolumn{7}{|l|}{ Modern } \\
\hline Pills & 28 & 47.4 & 258 & 50.5 & 286 & 47.7 \\
\hline IUD & 2 & 3.6 & 59 & 10.8 & 61 & 10.2 \\
\hline Injections & 5 & 7.4 & 40 & 8.9 & 45 & 7.5 \\
\hline Male condom & 0 & - & 24 & 4.4 & 24 & 4.0 \\
\hline Diaphragm & 0 & - & 13 & 2.4 & 13 & 2.2 \\
\hline Male sterilization & 0 & - & 3 & 0.6 & 3 & 0.5 \\
\hline Female sterilization & 1 & - & 0 & 1.8 & 1 & 0.2 \\
\hline \multicolumn{7}{|l|}{ Traditional } \\
\hline Breastfeeding & 19 & 33.9 & 175 & 32.2 & 194 & 32.3 \\
\hline Rhythm & 9 & 16.1 & 120 & 22.2 & 129 & 21.5 \\
\hline Withdrawal & 2 & 3.6 & 47 & 8.6 & 49 & 8.2 \\
\hline Other & 0 & - & 4 & 0.7 & 4 & 0.7 \\
\hline
\end{tabular}

${ }^{a}$ Not statistically significant for all methods.

IUD = intrauterine device.

Rural women reported using public outlet agencies as sources of family planning services much more than urban women (44.7\% and $29.9 \%$ respectively; $P=0.025)$, whereas urban women reported using the private sector much more than rural women $(21.2 \%$ and $10.7 \%$ respectively; $P=0.063)$. For women in rural areas, local health centres were the core source of services compared to women from urban areas $(37.5 \%$ and $19.9 \%$ respectively; $P=0.002$ ).

Child spacing was the main reason encouraging women to use family planning services $(58.4 \%)$, whereas the desire for more children was the main reason for not using these services. Very few women $(0.8 \%)$ reported that the use of contraception was against religious or cultural beliefs.

\section{Determinants of contraceptive use}

Compared with respondents who had poor knowledge about family planning, those who had good knowledge were significant- ly more likely to report a high level of using the modern methods $(P<0.001)$ (Table 3$)$.

Education level also had a statistically significant influence on the odds of the respondents using modern methods of contraception. Compared with those with no schooling; those with education were significantly more likely to report using contraception $(P=0.003)$. Socioeconomic status also appeared to play a significant role: women with a higher socioeconomic status were more likely than their counterparts to use modern methods of family planning. Area of residence and age did not appear to be associated with use of modern methods of family planning.

\section{Discussion and conclusions}

In the present study $51.4 \%$ of all women surveyed in the state of Khartoum used modern family planning methods. Compar- 


\begin{tabular}{|c|c|c|c|}
\hline Variable & $\operatorname{Exp}(B)$ & $P$-value & $\begin{array}{c}95.0 \% \mathrm{Cl} \\
\text { for } \operatorname{Exp}(\mathrm{B})\end{array}$ \\
\hline Knowledge $($ poor $=0$, good $=1)$ & 1.125 & $<0.001$ & $1.053-1.202$ \\
\hline Education (none $=0$ ) & & 0.003 & \\
\hline Primary & 2.371 & 0.003 & $1.331-4.224$ \\
\hline Intermediate & 2.695 & 0.002 & $1.424-5.100$ \\
\hline Secondary & 2.714 & 0.001 & $1.484-4.962$ \\
\hline University+ & 1.338 & 0.453 & $0.626-2.861$ \\
\hline Age & 1.024 & 0.147 & $0.992-1.056$ \\
\hline Residence (rural =0, urban $=1)$ & 0.600 & 0.107 & $0.322-1.116$ \\
\hline Socioeconomic level $($ low $=0$ ) & & $<0.001$ & \\
\hline Medium & 1.925 & 0.005 & $1.219-3.040$ \\
\hline High & 4.456 & $<0.001$ & $2.654-7.481$ \\
\hline Constant & 0.086 & & \\
\hline
\end{tabular}

$\mathrm{Cl}=$ confidence interval.

ing with recent studies in the northern states of Sudan, the utilization rate in Khartoum State is far greater. The level of use of any method of contraception varies from $<1.0 \%$ in Western Darfur State to $21.0 \%$ in Khartoum State [7]. This could be attributed to the fact that Khartoum is the capital of the country and socioeconomic status, education level, availability and capacity of health care services as well as supplies of available modern family planning methods are considerably better compared with other states of the country.

The 2 types of location, urban and rural, used modern methods of family planning almost equally. Only very few women use methods such as injection or male and female sterilization. Although international family planning efforts have successfully integrated male methods [15] such as condoms and sterilization into their various programmes, our findings demonstrated that use of these methods by males was extremely low. This might partly be explained by the fact that these methods are perceived as being in conflict with traditional culture, patriarchal norms, native notions of maleness and religious doctrine [16].

The study identified public outlet agencies as being particularly important sources of family planning services for women from urban as well as from rural areas. Contrary to what was expected for Sudan, an Islamic country in the developing world, very few women reported that the use of contraceptive methods was against religion or cultural beliefs.

The principal predisposing and enabling factors affecting utilization of modern family planning methods by women were socioeconomic status, knowledge, and education of the mother. This leads to the conclusion that the main limiting factors to the utilization of modern family planning methods in the state are poverty, ignorance, and illiteracy. The study has clearly evidenced that knowledge of family planning among

ألمجلة الصحية لشرق المتوسط، منظمة الصحة العالمية، المجلد الثالث عشر، العدد Y، V... 
married Sudanese women is far from being universal.

Although education was associated with increase in the use of modern family planning methods, a drop was noticed in women with university and higher education. This might partly be explained by the fact that these women start their family life after their education, i.e. at a later age, and try to have the number of children they wish before their menopause begins.

The findings of this study evidenced the need to empower the population through income-generation and improving standards of living. Increasing education might help in solving the income problem as well and would increase knowledge about modern family planning methods and hence, increase predisposition to their use. Basic education programmes must be effectively run for people who are illiterate. Specific programmes about family planning should be developed and implemented. Such programmes need to target urban as well as rural communities as in both areas women were found in conditions predisposing them for non-use of family planning. In order to satisfy the needs for family planning services, expansion of existing family planning services to cover all urban as well as rural areas is essential. Policy makers may introduce legislation that would make it easier for states to extend family planning services to reach more low-income women. Other efforts to provide coverage through establishing new family planning centres and clinics and providing existing ones with modern services are needed. Implementing efficient reproductive health programmes would also make a difference.
Apart from the development and implementation of programmes targeting women, planners might also attempt to overcome resistance of men to family planning methods. As a first step, research would be needed to analyse the psychosocial and cultural determinants of non-use and barriers to the use of modern family planning methods by men. Based on such research, concerted programmes could be developed to encourage men to participate in family planning and use modern male methods.

There were some limitations and shortcomings to our study that may qualify our results. The first was the exclusion of unmarried women from the sample, in spite of the fact that local religious values and norms prohibit sexual activities outside marriage, some unmarried women still get pregnant and seek induced abortions. The most important limitation of our study was that data about men on family planning was collected from their wives and not directly. Specially designed family planning research involving men would be needed to explore their role in family planning and in using male methods. Last, overlapping of some urban-rural localities of the country's capital city and similarities in standards of living in some of them may have affected the accuracy of the results regarding differences in utilization according to residence.

\section{Acknowledgements}

This study was supported by grants from the Government of Sudan and the University of Maastricht.

\section{References}

1. World health report, statistical annex. Geneva, World Health Organization, 2002.
2. Study group on programming for adolescent health. Geneva, World Health 
Organization, 1999 (Technical Report Series 886).

3. World population data sheet. Washington, DC, Population Reference Bureau, 1999.

4. Bulatao RA. The value of family planning programs in developing countries. Santa Monica, California, Rand, 1998.

5. Freedman R. Family planning programs in the third world. Annals of the American Academy of Political and Social Science, 1990, 510(1):33-43.

6. Effective family planning programs. Washington, DC, World Bank, 1993.

7. Safe motherhood survey, national report. Geneva, Federal Ministry of Health (Sudan), Central Bureau of Statistics, United Nations Population Fund, 1999.

8. Sudan demographic and health survey, 1989-1990. Khartoum, Sudan, Federal Ministry of Economic and National Planning, 1991.

9. Sudan maternal and child health survey, 1992/93. Khartoum, Federal Ministry of Health National Directorate of Motherhood, Childhood \& Family Planning, 1995.

10. Caldwell JC, Caldwell P. The cultural context of high fertility in sub-Saharan
Africa. Population and development review, 1987, 13(3):409-37.

11. Frank $O$, McNicoll G. An interpretation of fertility and population policy in Kenya. Population and development review, 1987, 13(2):209-43.

12. Ramesh BM, Gulati SC, Retherford RD. Contraceptive use in India, 1992-1993. Mumbai, India, International Institute for Population Sciences \& East-West Center, 1996 (National Family Health Survey Subject Reports, No. 2).

13. Dutton D. Financial, organisational and professional factors affecting health care utilisation. Social sciences and medicine, 1986, 23(7):721-35.

14. Andersen R, Newman JF. Societal and individual determinants of medical care utilization in the United States. Milbank Memorial Fund quarterly, 1973, 51(1):95123.

15. Ali KA. Modernization and family planning programs in Egypt. Middle East report, 1997, 205:40-4 (http://www.merip.org/ mer/mer205/kamran.htm, accessed 12 August 2007).

16. Seltzer JR. The origins and evolution of family planning programs in developing countries. Santa Monica, California, Rand, 2000:185. 